\title{
Analysis of a Trombe Wall Prototype with Thermal Energy Storage and Air Vent Management
}

\author{
Abdallah Alshantaf, Harmeet Singh, Paul O'Brien \\ Department of Mechanical Engineering, Lassonde School of Engineering, York University \\ Toronto, Ontario, M3J 1P3, Canada \\ Ak.alshantaf@gmail.com; harmeet.singh245@gmail.com;paul.obrien@ lassonde.yorku.ca
}

\begin{abstract}
Thermal energy storage (TES) mediums can be integrated into Trombe walls to improve the utilization of solar energy to offset building energy loads. The vents at the top and bottom of a Trombe wall can be used to manage the flow of heated air through a Trombe wall to store and deliver thermal energy to match the demand profile in buildings. Herein we investigate the thermal energy stored in fire-clay bricks as a sensible storage medium integrated into a scaled Trombe wall prototype. After 3.8 hours under a solarsimulated light source at an intensity of $\sim 325 \mathrm{~W} / \mathrm{m}^{2}, \sim 33 \mathrm{MJ} / \mathrm{kg}$ is stored in the fireclay bricks when the vents are open. In comparison, $\sim 37 \mathrm{MJ} / \mathrm{kg}$ is stored in the fireclay bricks under similar experimental conditions when the vents are closed. During the discharging phase, which begins when the light source is turned off, it takes $\sim 3.5$ hours for the amount of thermal energy stored in the fireclay bricks to decrease by 50\% when the vents in the Trombe wall prototype are open. On the other hand, it takes $\sim 4.4$ hours for the amount of thermal energy stored in the fireclay bricks to decrease by $50 \%$ when the vents are closed. Improved management of solar thermal energy in Trombe walls can reduce the carbon footprint of residential and commercial buildings.
\end{abstract}

Keywords: Thermal Energy Storage, Trombe Wall, Solar Energy, Computational Fluid Dynamics

\section{Introduction}

The building sector accounts for 30\% of the global energy consumption [1] and for more than $40 \%$ of total energy consumption in the European Union [2]. Furthermore, about $70 \%$ of the fuel used for heating, cooling, and hot water in buildings is derived from burning fossil fuels [3]. The solar irradiance, which provides more energy at the earth's surface than the global annual energy consumption, is widely recognized as a clean energy source that should be utilized to reduce energy consumption in buildings [1, 4-9]. However, solar energy is intermittent, and should be paired with Thermal Energy Storage (TES) systems to best provide for the energy demand profile in buildings [10]. TES systems provide a wide range of opportunities and benefits to reduce energy consumption and GHG emissions along the road to a sustainable, productive, environmentally friendly, and low-carbon building sector [11,12]. Although TES materials alone do not provide instant heating or cooling as a mechanical system does, they can be designed, through selection of materials, thicknesses and configuration, to offset building energy loads. In addition, peak loads can be reduced in summer and winter months by increasing the thermal inertia of the building, and in intermediate months, cooling and heating energy needs can be decreased [13].

The integration of TES materials in a Trombe wall can further enhance building energy performance. Trombe walls absorb sunlight that passes through a glass cover. There are vents at the top and bottom of the Trombe wall and the heat generated within the Trombe wall induces a natural airflow that can be used to carry hot air into the building [14,15]. It has been recognized that control over when the Trombe wall vents are open and closed can enhance the ability of the Trombe wall to meet building energy demand profiles. For example, Liu et. al. have shown that Trombe wall vents should be opened 2-3 $\mathrm{h}$ after sunrise and $1 \mathrm{~h}$ before sunset for optimal performance [16]. However, more research in this area is required to determine the optimal vent operation in different Trombe wall designs and under varying solar irradiance and climate conditions [17]. Herein we experimentally and numerically investigate the potential for storing solar thermal energy within a Trombe wall prototype operating with open or closed vents. This Trombe wall utilizes fireclay bricks, a solid sensible heat storage material. This TES medium provides thermal reliability (no change in thermal properties), chemical stability (no decomposition or change in chemical composition after a large number of thermal cycles), and thermal stability (no degradation or weight loss at high temperatures). Results show that $50 \%$ of the solar thermal energy 
stored in the Trombe wall prototype can be retained after removing the light source for a duration of 4.4 hours when the Trombe wall vents are closed as compared to 3.5 hours for the case when the Trombe wall vents are open.

\subsection{Trombe Wall Experimental Model}

The Trombe wall prototype is shown in Figure 1. This model was built using $3.8 \times 3.8 \mathrm{~cm}$ wooden frames because of their low thermal conductivity. The overall dimensions of the model frame is $58.4 \times 38.1 \times 66.0 \mathrm{~cm}$. The frame is insulated using 1.5-inch thick FOAMULAR extruded polystyrene insulation boards. Silicon sealant was used to assemble the prototype. The front surface of the Trombe wall prototype was made from a $3 \mathrm{~mm}$ thick clear acrylic sheet that was tightly fitted in the insulation board frame and then sealed using silicon sealant at its edges. These seals were subsequently covered with sheathing tape. The side of the Trombe wall prototype was designed as an insulated door to allow users to change the TES medium and adjust other parameters including the dampers on the air vents.

The TES medium used in this work is fire clay bricks. There is a total of 18 fire clay bricks in the setup ( 2 bricks across $\mathrm{x} 3$ deep x 3 high) that are used to store and release heat. The dimensions of each brick is $5 \times 10 \times 22.5 \mathrm{~cm}$, making the overall volume of the bricks $15 \times 45 \times 30 \mathrm{~cm}$. Black spray paint was applied to the front surface of the bricks to increase the amount of light they absorb. Two 4 in x 11 in ducted air vents are located at the back of the Trombe wall model above and below the fireclay bricks to allow for air flow through the Trombe wall prototype and across the front face of the bricks. The air vents are made of standard 4 in diameter ducts that extend to the ambient air of the lab. The Trombe wall prototype is mounted with the acrylic side facing a solar simulator light bulb. The light bulb is a $1000 \mathrm{~W}$ Hortilux Blue W Metal Halide bulb mounted vertically with a reflector behind it. This light source is $35.6 \mathrm{~cm}$ away from the front surface of the acrylic sheet.

Type $\mathrm{K}$ thermocouples were mounted in locations of interest to analyze the thermal energy storage potential of the fireclay bricks within the Trombe wall prototype. The first thermocouple is installed at $5 \mathrm{~cm}$ from the glass and attached to the top insulation panel, which is used to measure the highest temperature in the air gap. The second thermocouple is mounted at the front surface of the bricks; the third thermocouple is mounted at the back of the first brick. The final thermocouple is mounted at the back of the bricks at the brick-insulation interface. The positions of the thermocouples are shown in Figure 2a.
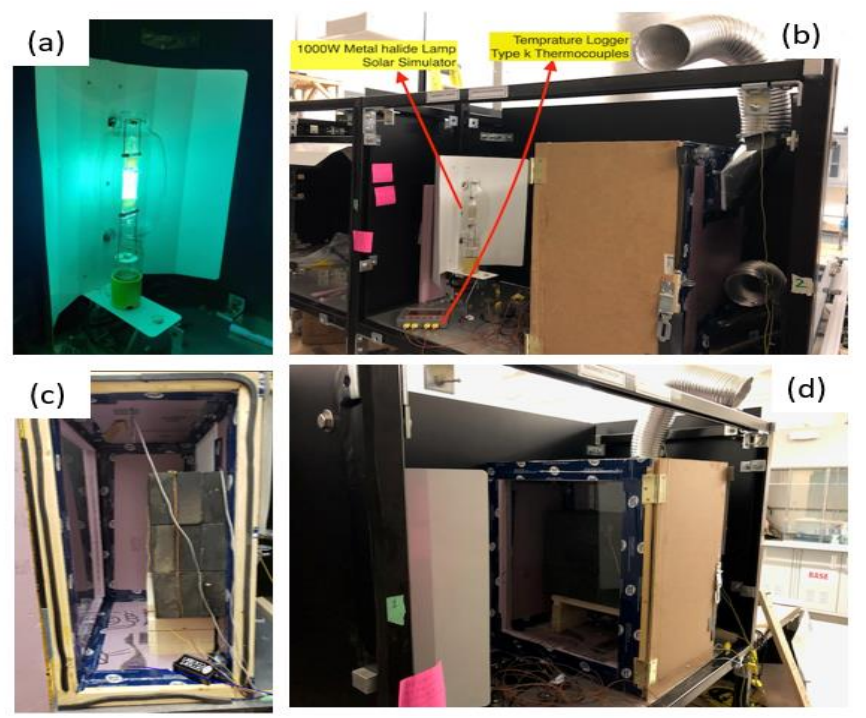

Figure 1: (a) 1000W metal halide light functioning as a solar simulator, (b) Isometric view of the experimental setup, (c) Side view of the Trombe wall prototype and TES medium, (d) front facing view of the experimental setup 


\subsection{Experimental Method}

Experiments were conducted to determine the effects of operating the vents in open and closed positions on the temperature profile of the TES medium. Herein, we refer to the time durations when the light is on and off as the charging and discharging phases, respectively. Experiments were performed with (1) the vents closed while charging and open while discharging, (2) the vents open during both the charging and discharging phases, and (3) the vents closed during both the charging and discharging phases.

Before initiating an experiment, it was ensured that all thermocouples were properly mounted in their positions. The air vents and Trombe wall door were then closed before turning on the thermocouple logger to record the temperature. The $1000 \mathrm{~W}$ metal halide bulb was then turned on and the temperature was continuously recorded, every 10 seconds, over the duration of the experiment. After about 4 hours the metal halide light bulb is switched off, and the temperature continued to be recorded as the system cooled. For the experiment wherein the vents are closed and open during the charging and discharging phases, respectively, the vents were opened at the same time the light was switched off.

\subsection{Analytical Method}

A two-dimensional model of the Trombe wall prototype was first setup using Ansys Fluent. As shown in Figure 2a, the model consists of an air gap, an acrylic panel, and bricks as the TES medium. Furthermore, in this model the Trombe wall prototype is situated within a room of width $1.3 \mathrm{~m}$ and height $0.8 \mathrm{~m}$ that is filled with air (to represent the enclosure in which the prototype resides). 


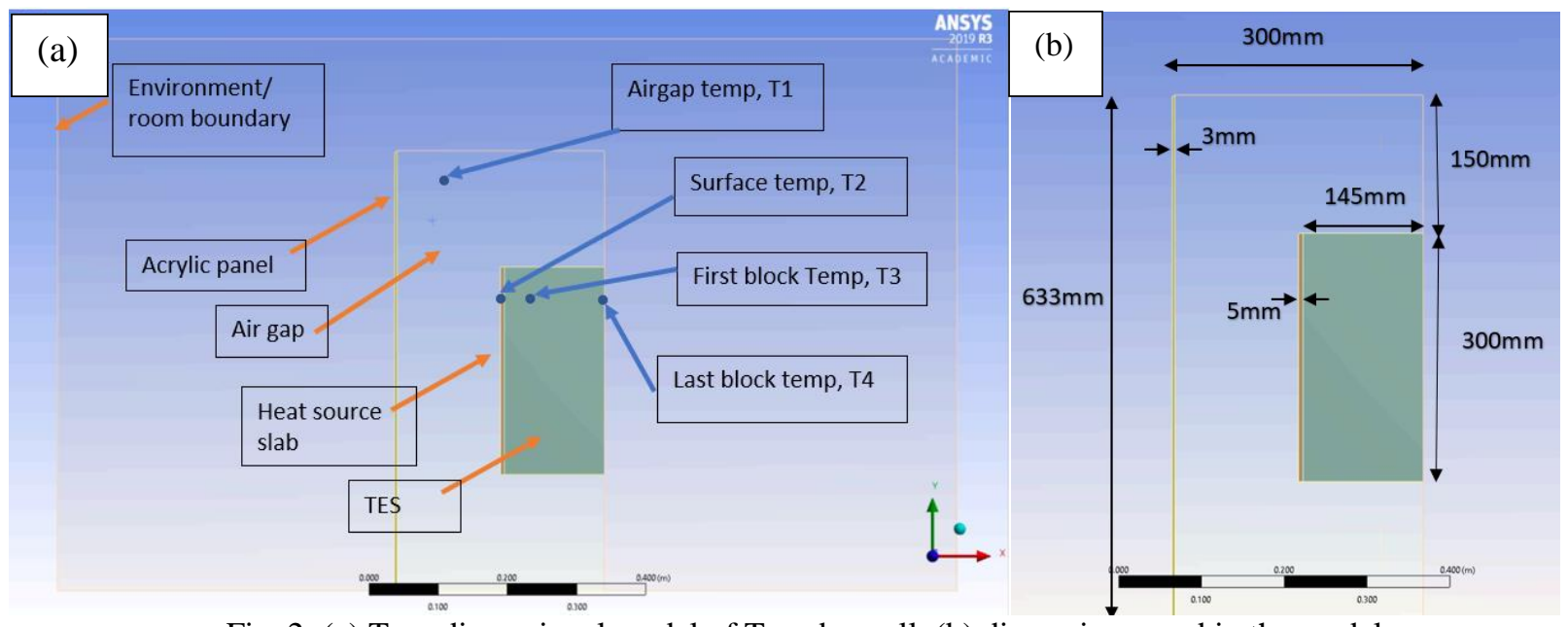

Fig. 2: (a) Two-dimensional model of Trombe wall, (b) dimensions used in the model

The dimensions used for the Trombe wall prototype in the 2D model are shown in Figure $2 \mathrm{~b}$. The dimensions of the Trombe wall prototype are $633 \times 300 \mathrm{~mm}$. The front face (left side) of the Trombe wall prototype is an acrylic sheet with dimensions of $3 \times 633 \mathrm{~mm}$. The TES medium occupies the green $45 \times 300 \mathrm{~mm}$ square at the rear side of the Trombe wall prototype. The properties of the materials used in the ANSYS simulation are provided in Table 1.

Table 1: Properties of the materials used in the ANSYS simulation

\begin{tabular}{|c|c|c|c|c|}
\hline $\begin{array}{r}\text { M } \\
\text { aterial }\end{array}$ & Density $\left(\mathrm{kg} / \mathrm{m}^{3}\right)$ & $\begin{array}{l}\text { Thermal } \\
\text { conductivity } \\
(\mathrm{W} / \mathrm{m} \cdot \mathrm{k})\end{array}$ & $\begin{array}{l}\text { Specific heat } \\
(\mathrm{J} / \mathrm{kg} \cdot \mathrm{k})\end{array}$ & $\begin{array}{l}\text { Viscosity } \\
(\mathrm{kg} / \mathrm{m} \cdot \mathrm{s})\end{array}$ \\
\hline $\mathrm{r}^{\mathrm{Ai}}$ & $\rho=\frac{p_{\mathrm{op}}^{*}}{\frac{R}{M_{w}} T}$ & 0.0242 & 1006.43 & $1.7894 \mathrm{e}-5$ \\
\hline $\begin{array}{l}\mathrm{Br} \\
\text { icks }\end{array}$ & 1920 & 0.9 & 790 & N/A \\
\hline $\begin{array}{l}\text { Ac } \\
\text { rylic }\end{array}$ & 1390 & 0.2 & 1360 & N/A \\
\hline
\end{tabular}

To represent the light energy absorbed and converted to heat, a $5 \mathrm{~mm}$ thick heat generation slab is situated at the front face of the TES medium. The heat generation rate in this slab is set to be equivalent to the radiant power from the lamp that is incident onto the TES medium. The average incident light intensity during the experiments was $326.1 \mathrm{~W} / \mathrm{m}^{2}$. The front surface of the TES medium, which is illuminated by solar-simulated light, has an area of $0.3 \times 0.45 \mathrm{~m}=0.135 \mathrm{~m}^{2}$. Using this light intensity and surface area it is assumed that $44.02 \mathrm{~W}$ of light energy is absorbed and converted to heat at the front face of the bricks. The heat generation rate in the $5 \mathrm{~mm}$ thick heat generation slab at the front of the TES medium is then determined using the equation below:

$$
\frac{Q}{\mathrm{~m}^{3}}(\text { heat generation rate })=\frac{44.02 \mathrm{~W}}{0.45 \mathrm{~m} * 0.3 \mathrm{~m} * 0.005 \mathrm{~m}}=65214.8 \frac{\mathrm{W}}{\mathrm{m}^{3}}
$$

The mesh used to carry out the simulations is shown in Figure 3. The mesh consists of quadrilateral cells of varying sizes within the domain. In the TES medium (i.e. the fireclay bricks) the element size remains constant at $5 \mathrm{~mm}$. In the heat 
generation slab the size of the mesh element is $2.5 \mathrm{~mm}$. In the outer domain that represents the surrounding environment, the element size was $10 \mathrm{~mm}$ with a growth rate of 1.2 from the edges of the Trombe wall.

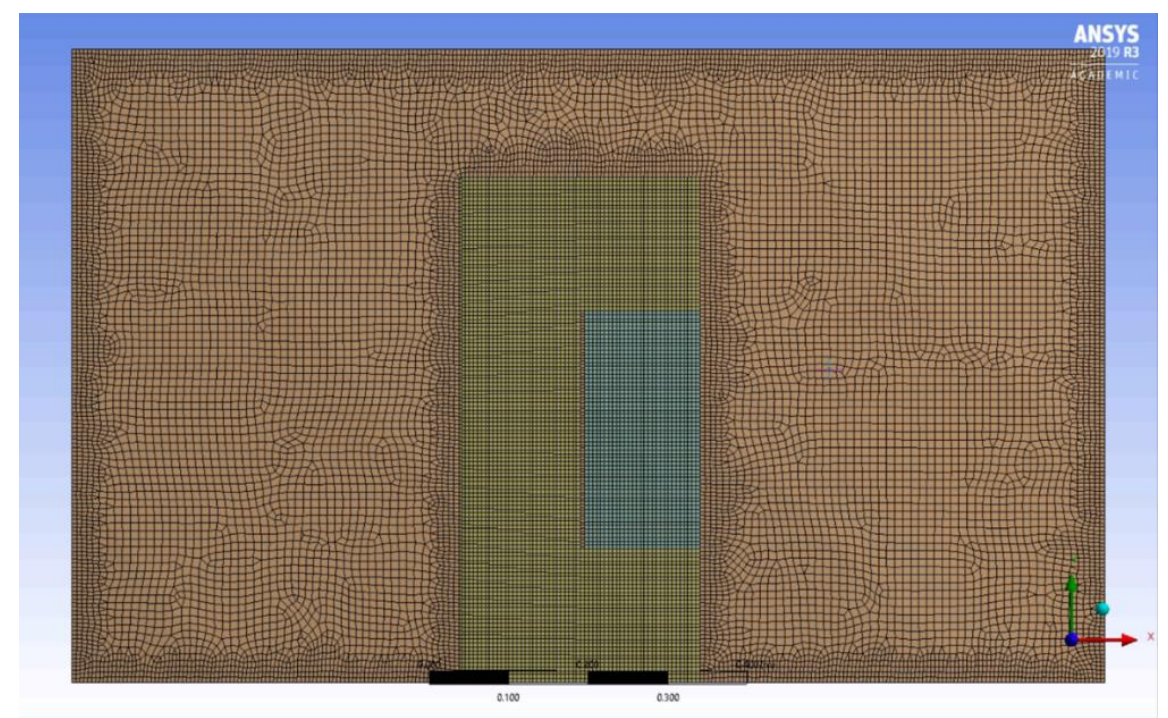

Figure 3: Ansys mesh of the Trombe wall prototype

For all simulations it was assumed that the top, bottom, and right side of the Trombe wall were perfectly insulated and there is zero heat flux through these surfaces. A pressure outlet wall boundary condition is assigned at the outer surfaces of the surrounding environment. The ambient temperature is set to $293 \mathrm{~K}$ which is also the initial temperature for the entire domain. The simulation was ran in transient mode for about four hours with the heat source generating $65214.8 \mathrm{~W} / \mathrm{m}^{3}$. The power from the heat source was then set to zero, which is consistent with turning off the light source in the experiments. Furthermore, simulations were performed with the same boundary conditions and settings, but with the mesh sizes $20 \%$ smaller than that shown in Figure 3 across all domains to ensure the results are independent of the mesh size. The results for the case when the mesh size was $20 \%$ smaller differed by less than $1 \%$ as compared to the results attained using the original mesh sizes.

\section{Results}

\subsection{Experimental Results}

The resulting temperature profiles for the first case, wherein the Trombe wall vents are closed while the solar-light is on, and then opened when the light is turned off at the four-hour mark, are shown in Figure 4. The initial temperature was $22.8{ }^{\circ} \mathrm{C}$, and at the end of the charging time the front surface temperature had increased to $55.2{ }^{\circ} \mathrm{C}$. Using the temperature of the first brick as an approximation for the average temperature of the TES medium, a first order estimate of the total heat stored during the charging time was acquired using the following formula:

$$
Q=\int_{T_{i}}^{T_{f}} m * c p * d T
$$

For the first case the total energy stored during the charging phase is then estimated to be $670 \mathrm{~kJ}$. The ducts were opened when the light source was turned off, allowing air to flow through the Trombe wall prototype via natural convection. 3.5 hours after the light had turned off the thermal energy stored in the fireclay bricks had reduced by $50 \%$. 


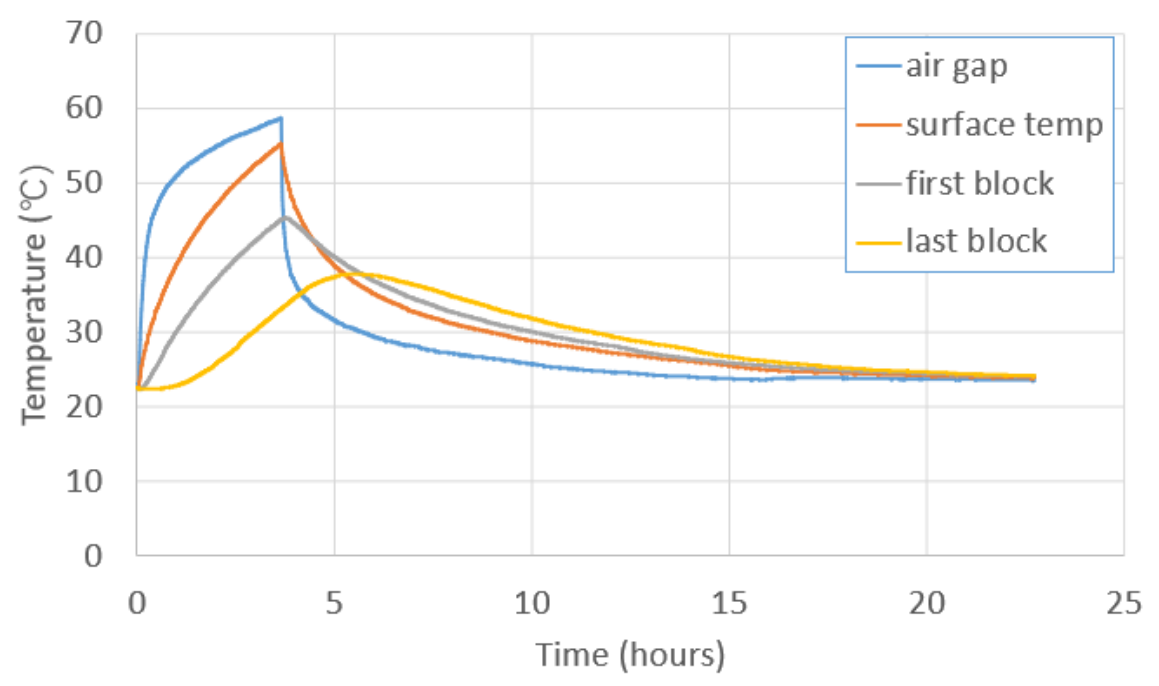

Fig. 4: Temperature profiles in the Trombe wall prototype for the case when the vents are closed while the solar simulator is on, and then opened when the solar simulator is turned off.

Figure 5 plots temperature vs time at the thermocouple positions indicated in Figure 3a for the case in which the vents at the back of the Trombe wall are open over the entire duration of the experiment. In this case the initial temperature was $22.5{ }^{\circ} \mathrm{C}$. The temperature at the front surface of the bricks increased to $50.3{ }^{\circ} \mathrm{C}$ over the four-hour duration when the light was on. The temperature at the first brick when the light was turned off was $44.1{ }^{\circ} \mathrm{C}$, and the total energy stored at this point was estimated to be $640 \mathrm{~kJ}$. Thus, as compared to the case when the vent was closed, natural convective cooling through the open vents resulted in a decrease in the amount of thermal energy stored of $\sim 30 \mathrm{~kJ} .3$ hours after the light had turned off the thermal energy stored in the bricks had reduced by $50 \%$.

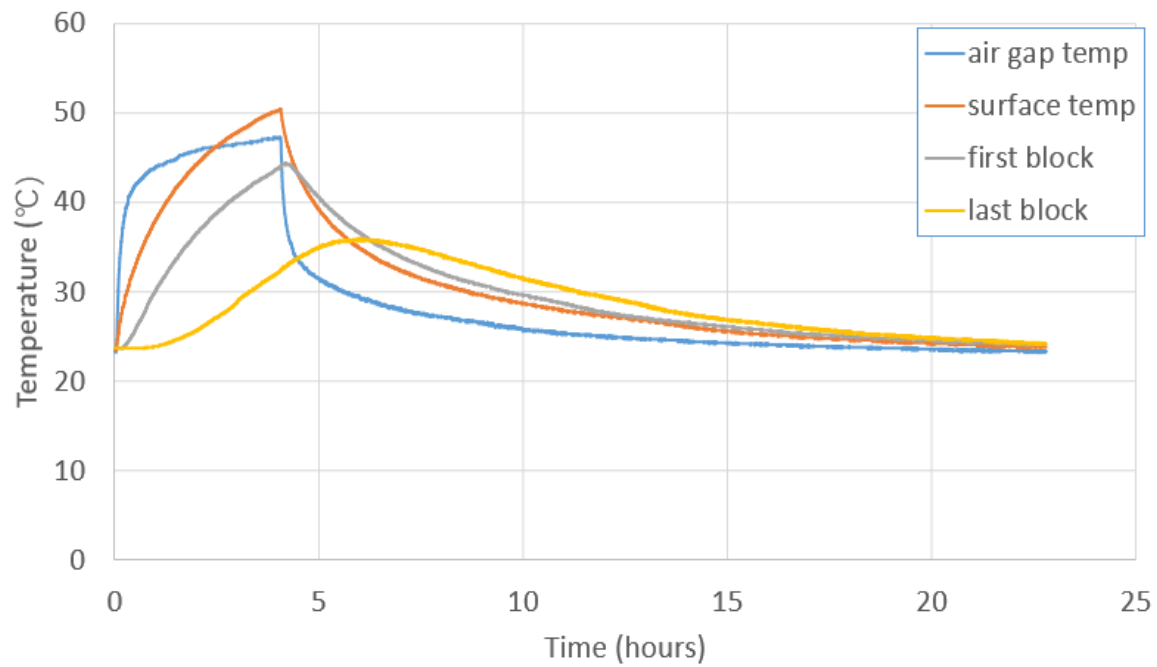

Fig. 5: Temperature profiles in the Trombe wall prototype for the case when the vents are open for the entire duration of the experiment.

The temperature profiles for the third case, wherein the Trombe wall vents were closed for the entire experiement, are shown in Figure 6. The initial temperature when the light was turned on was $23.6^{\circ} \mathrm{C}$. When the light was turned off after almost four hours the temperature at the front surface of the bricks was $57.1^{\circ} \mathrm{C}$. The temperature of the bricks and amount of energy stored in the bricks at the time the light was turned off was $47.8^{\circ} \mathrm{C}$ and $750 \mathrm{~kJ}$, respectively. 4.4 hours after the light had turned off the thermal energy stored in the bricks had reduced by $50 \%$. 


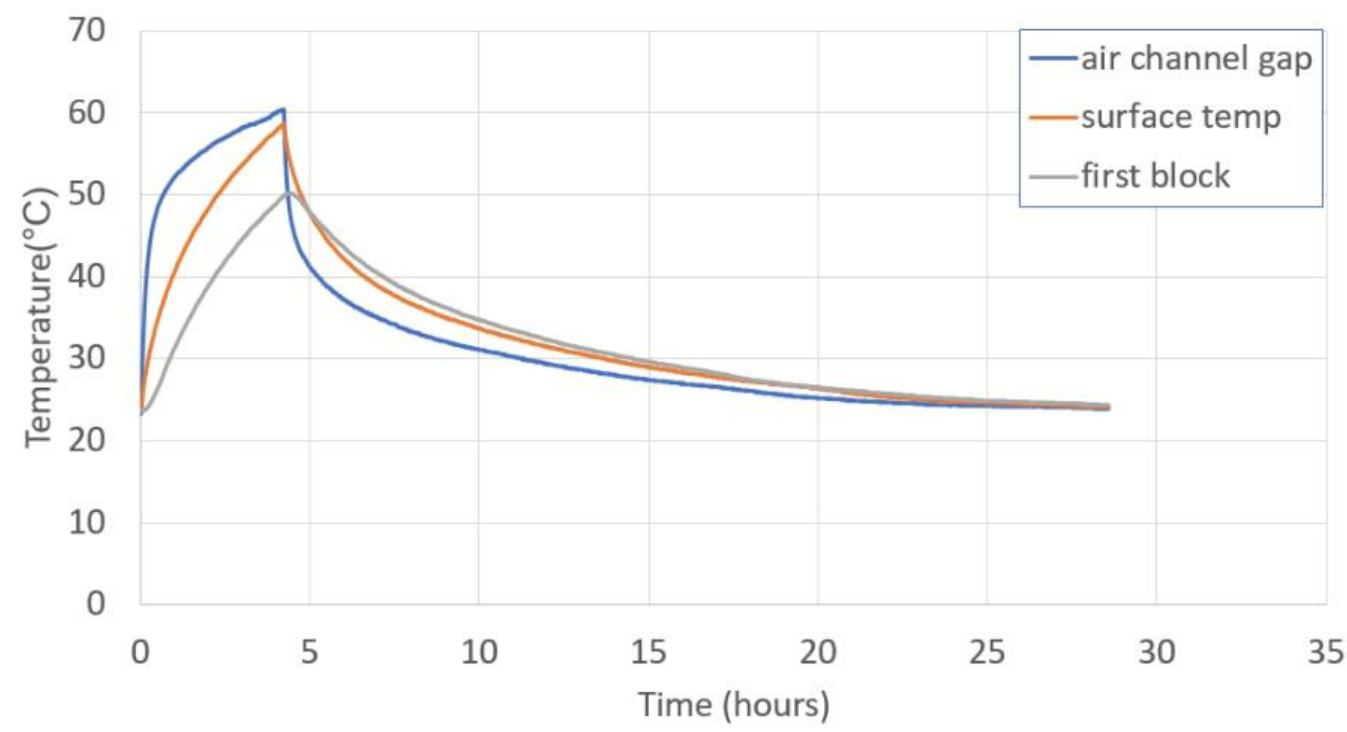

Fig. 6: Temperature profiles in the Trombe wall prototype for the case when the vents are open for the entire duration of the experiment. (The temperature profile at the last block is not available for this case due to thermocouple malfunction)

Table 2: Summary of selected results for the three cases studied

\begin{tabular}{|c|c|c|c|}
\hline Case & Closed-Open & Open-Open & Closed-Closed \\
\hline Air gap temperature after light is on for $3.8 \mathrm{~h}\left({ }^{\circ} \mathrm{C}\right)$ & 58.7 & 47.2 & 59.4 \\
\hline Surface temperature after light is on for $3.8 \mathrm{~h}\left({ }^{\circ} \mathrm{C}\right)$ & 55.2 & 50.3 & 57.1 \\
\hline First block temperature after light is on for $3.8 \mathrm{~h}\left({ }^{\circ} \mathrm{C}\right)$ & 45.1 & 44.1 & 47.8 \\
\hline Energy stored after light is on for $3.8 \mathrm{~h}(\mathrm{~kJ})$ & 670 & 640 & 750 \\
\hline Energy stored after light is on for $3.8 \mathrm{~h}\left(\mathrm{MJ} / \mathrm{m}^{3}\right)$ & 33.0 & 31.6 & 37.0 \\
\hline $\begin{array}{c}\text { Time taken (after light turned off) to lose } 50 \% \text { of the } \\
\text { energy stored (h) }\end{array}$ & 3.5 & 3.0 & 4.4 \\
\hline
\end{tabular}

Table 2 summarizes the experimental results for all three test cases. The data shows an increase in the air gap temperature, surface temperature and energy stored after the light had been on for 3.8 hours for the cases when the vents were closed during the charging phase. As expected, the energy stored 3.8 hours after the light was on for the cases wherein the vents were closed during the charging phase are greater than that for case 2 , wherein the vents were closed during the charging phase. However, there is a large difference between the energy stored at the 3.8-hour mark for cases 1 and $3(670 \mathrm{~kJ}$ vs $750 \mathrm{~kJ})$. It was expected that these measured values should be closer, because the experimental conditions for the two test cases are identical for the first 3.8 hours of the experiment. One factor contributing to this difference may be the temperature of the surroundings at the beginning of the experiment, which was $22.8{ }^{\circ} \mathrm{C}$ and $23.6{ }^{\circ} \mathrm{C}$ for test cases 1 and 3, respectively. When the ducts were closed during the discharging phase the energy stored in the fireclay bricks was retained for a longer amount of time. That is, from the time the light was turned off it took $4.4 \mathrm{~h}$ for the amount of thermal energy stored to be reduced by $50 \%$ for test case 3 . On the other hand, it took 3.5 and 3 hours for the amount of energy to 
decrease by $50 \%$ from the time the light was turned off for cases 1 and 3, wherein the vents were open during the discharging phase.

\subsection{Simulation Results}

The simulations were carried out for the third case, wherein the vents on the rear side of the Trombe wall were closed while the light was on and off. The temperature at the points indicated in Figure $3 \mathrm{a}$ are plotted as a function of time in Figure 7a. The initial temperature was set to $293 \mathrm{~K}$. At the 4-hour mark when the light was turned off (e.g. the heat generation in slab at the front face of the TES medium was set to zero) the surface temperature of the bricks was $56{ }^{\circ} \mathrm{C}$ and the temperature of the last brick was $34{ }^{\circ} \mathrm{C}$. The total heat stored in the bricks at the 4-hour mark was $676 \mathrm{~kJ}$. Even though the simulations are carried out in $2 \mathrm{D}$, the surface temperature of the bricks at the end of the charging phase was similar to that from the experiments.
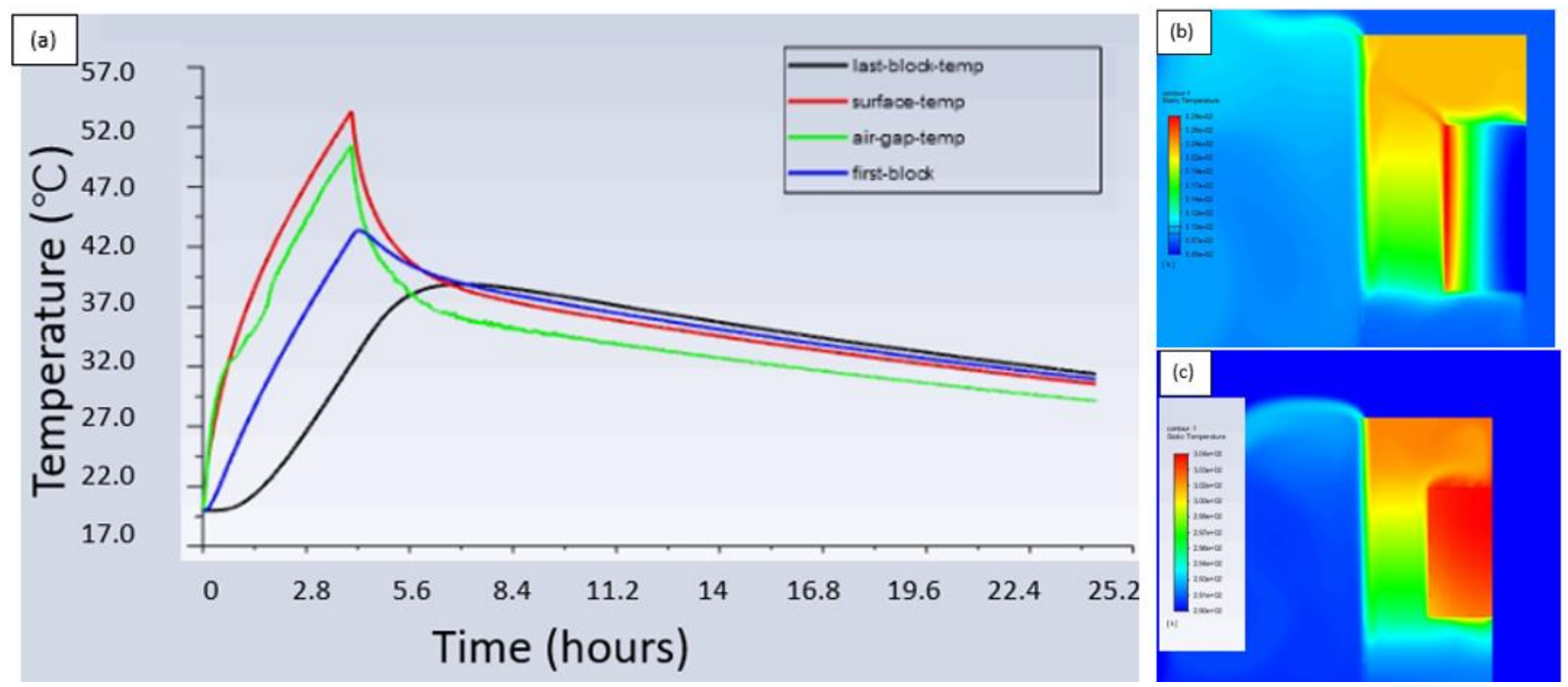

Figure 7: (a) Temperature plot over time, (b) Temperature contour at the 4-hour mark (ranges from blue $305 \mathrm{~K}$ to red 329K), (c) Temperature contour after 20 hour cooling time (ranges from blue $209 \mathrm{~K}$ to red $304 \mathrm{~K}$ ).

\section{Discussions}

\subsection{Experimental Results}

The trends recorded during the charging phase, when the light source is on, are similar for all three cases. The radiation from the light source strikes the front surface of the bricks which raises its temperature. Heat then transfers to the second and third rows of blocks at a decreasing rate. As shown in Table 2, the temperature at the top of the air-channel is about $10{ }^{\circ} \mathrm{C}$ higher at the end of the charging phase when the vent is closed as compared when it is open. Also shown in Table 2, as expected, thermal energy can be stored for a longer duration after the solar-simulated light source has been removed by closing the vents. These results suggest that closing vents can be used as a simple way to retain thermal energy in Trombe walls such that thermal energy can be provided after sunset, which better-matches the heat demand profile for many buildings. Future experimental work will investigate the effects of altering the dimensions of the Trombe wall prototype, applying forced airflow (e.g. using a fan in the vents), and using different TES mediums, such as latent heat storage materials. 


\subsection{Simulation Results}

Simulations can assist with the rapid investigation and optimization of Trombe wall geometries, materials, and operation under different environments with vents in the opened or closed position. Initial two-dimensional simulation results for the Trombe wall prototype are presented in Section 3.2 for the case in which the vents are in the closed position during both the charging and discharging phases. The trends in the simulation (Fig 7) are well matched to those observed in the experiment (Fig 6), although there are some significant differences. The cooling rate during the discharging phase is much lower for the simulations as compared to the experimental results. This may be due to the fact that the simulations are carried out in two-dimensions and the assumption that the upper, lower, and rear sides of the Trombe wall are perfect insulators. Nevertheless, the results achieved in these initial simulations by using a heat generation medium to represent the solar-thermal energy generated at the front face of the Trombe wall shows promising similarities to results observed during the charging phase in the experiments. Further work is required to improve the model, initially to validate that it can be used to represent experimental data for the Trombe wall prototype and subsequently for full-size Trombe walls. Future work can also focus on improving the simulations to investigate the effects of using forced airflow (e.g. by equipping the Trombe wall vents with a fan) to optimize the delivery of solar energy from the Trombe wall to the building interior.

\section{Conclusions}

The TES medium within the Trombe wall prototype is able to store and deliver heat at different rates by operating the vents in open and closed positions. When the vents within the Trombe wall prototype were open, $637.8 \mathrm{~kJ}$ of energy was stored in the TES medium after being subjected to solar-simulated radiation at an intensity of $326.1 \mathrm{~W} / \mathrm{m}^{2}$ for $3.8 \mathrm{hours}$. When the vents were closed while the TES medium was subjected to solar-simulated radiation for 3.8 hours, $748.5 \mathrm{~kJ}$ was stored. Results from two-dimensional numerical simulations performed in Ansys Fluent showed that $676 \mathrm{~kJ}$ are stored in the TES medium. Also, after the light source had been removed, thermal energy was stored in the Trombe wall prototype for a longer duration by having the vents closed. That is, $50 \%$ of the stored energy had been lost from the fireclay bricks within the Trombe wall after $\sim 3.5$ and $\sim 4.4$ hours when the vents were in the open and closed positions, respectively. Thermal management in Trombe walls using simple techniques such operating its vents has potential for reducing greenhouse gas emissions in the building sector.

\section{Acknowledgment}

This research was funded by the Lassonde School of Engineering Undergraduate Research Award (LURA) and the Natural Sciences and Engineering Research Council of Canada (NSERC). The authors acknowledge the assistance of Behdad Rezanejadzanjani and Khaled Youssef during the simulation part of this project. Extended acknowledgments go to Kapil Narwal for his help in the manufacturing, modeling, and data collection phase.

\section{References}

[1] International Energy Agency. (2020, 8 October) Energy Technology Perspectives 2020. [Online]. Available: https://www.iea.org/reports/energy-technology-perspectives-2020/clean-energy-technologies-the-state-of play\#abstract

[2] The European Parliament and the Council of the European Union. "Directive2010/31/EU of the European Parliament and of the Council of 19 May 2010 on the Energy Performance of Building (recast)," Official Journal of the European Union; 2010.

[3] International Energy Agency, "Transition to Sustainable Buildings. Strategies and Opportunities to 2050.", OECD/IEA; 2013.

[4] G. Tsalikis, G. Martinopoulos, "Solar Energy Systems Potential for Nearly Net Zero Energy Residential Buildings", Solar Energy, vol. 115, pp. 743-756, 2015.

[5] C. Lamnatou, D. Chemisana, R. Mateus, M. G. Almeida, S. M. Silva, "Review and perspectives on life cycle analysis of solar technologies with emphasis on building-integrated solar thermal systems" Renewable Energy, vol.75, pp.833$846,2015$. 
[6] Q. Daigle, P. G. O’Brien, "Heat Generated Using Luminescent Solar Concentrators for Building Energy Applications", Energies, vol.13, No.21, p. 5574, 2020.

[7] P. G. O’Brien, A. Chutinan, P. Mahtani, K. Leong, G. A. Ozin, N. P. Kherani, "Selectively transparent and conducting photonic crystal rear-contacts for thin-film silicon-based building integrated photovoltaics" vol. 19, pp.17040-17052, 2011.

[8] A. Buonomano, C. Forzano, S. A. Kalogirou, A. Palombo, "Building-façade integrated solar thermal collectors: Energy-economic performance and indoor comfort simulation model of a water based prototype for heating, cooling, and DHW production", Renewable Energy, vol.137, pp. 20-36, 2019.

[9] M. S. Karimi, F. Fazelpour, M. A. Rosen, M. Shams, "Comparative study of solar-powered underfloor heating system performance in distinctive climates" Renewable Energy vol. 130, pp. 524-535, 2019.

[10] J. Lizana, R. Chacartegui, A. Barrios-Padura, C. Ortiz, "Advanced Low-Carbon Measures Based on Thermal Energy Storage in Buildings: A Review" Renewable and Sustainable Energy Reviews vol.82, pp. 3705-3749, 2018.

[11] I. Sarbu, C. Sebarchievici, “A comprehensive review of thermal energy storage” Sustainability vol. 10, pp.191, 2018

[12] J. Lizana, R. Chacartegui, A. Barrios-Padura, J. M. Valverde, "Advances in thermal energy storage materials and their applications towards zero energy buildings: A critical review" Applied Energy,vol. 203, pp.219-239, 2017.

[13] Al-Sanea SA, Zedan MF, Al-Hussain SN. "Effect of thermal mass on performance of insulated building walls and the concept of energy savings potential". Appl Energy 2012;89:430-42.http://dx.doi.org/10.1016/j.apenergy.2011.08.009..

[14] O. Saadatian, K. Sopian, C.H. Lim, N. Asim, M. Y. Sulaiman, "Trombe walls: A review of opportunities and challenges in research and development" Renewable and Sustainable Energy Reviews, vol.16, pp. 6340-6351, 2012.

[15] Z. Hu, W. He, J. Ji, S. Zhang, "A review on the application of Trombe wall systems in buildings" Elsevier, vol.70, pp. 976-987, 2017.

[16] Y. Liu, D. Wang, C. Ma, J. Liu, "A Numerical and Experimental Analysis of the Air Vent Management and Heat Storage Characteristics of a Trombe Wall" Solar Energy, vol.91 (2013) 1-10.

[17] A. B. Sá, J. Boaventura-Cunha, J. Lanzina, A. Paiva, "An experimental analysis of the Trombe wall temperature fluctuations for high range climate conditions: influence of ventilation openings and shading devices," Energy and Buildings, vol. 138, pp. 546-558, 2017. 